\title{
Miris kiše: kadrovska politika tranzicionog bibliotekarstva na brdovitom Balkanu
}

\author{
Saša Madacki \\ Univerzitet u Sarajevu \\ sasa.madacki@unsa.ba
}

\begin{abstract}
Sažetak
Svako sažimanje ovog teksta je zaludan posao. Ali, kako urednica insistira, moram da napišem o čemu se ovdje zapravo radi. Dakle, autor (tojest ja) u ovom radu donosi analizu kadrovske politike u bibliotekama Kantona Sarajevo gledanu kroz rakurs teorije magijskog realizma kao jedinog mogućeg okvira za objašnjenje fenomena zapošljavanja u bibliotečkoj struci. Autor daje drugo čitanje podataka prikupljenih u sistematskom istraživanju stanja biblioteka osnovnih i srednjih škola Kantona Sarajevo, kroz prizmu Strategije Međunarodne federacije bibliotečkih asocijacija i ustanova za period 2019-2024.
\end{abstract}

Ključne riječi: biblioteke, kadrovska politika, školske biblioteke, Bosna i Hercegovina, magijski realizam

\section{Uvod}

Pisati o bibliotekama, bibliotekarima i bibliotekarstvu na Balkanu i pritom ostati ozbiljan, iziskuje iznimno puno energije. ${ }^{1}$ Zahtjevi savremenih časopisa za univerzalnim naučnim pristupom obradi teme, elaboracijom najnovijih postignuća u teoriji i praksi nauke o bibliotekarstvu, inkorporiranju manifesta, smjernica i preporuka Međunarodne federacije bibliotečkih asocijacija i ustanova, suprotstavljeni lokalnom relativizmu začudnog zakonskog okvira i državnih budžeta na nivou izdašnijeg džeparca te kadrovskoj politici koju karakteriše post-razumski kadrovizam dovode autora u žestoku dilemu: pisati o bibliotekarstvu ili ostati normalan? Odnosno, pristojnije rečeno, kako pisati o bibliotekarstvu danas, a ne proizvoditi neugodni utisak da autor živi pod staklenim zvonom lišen kontakta sa realnošću?

Nakon vrlo dugog promišljanja (koje je urednicu uspjelo izbaciti iz snažno zapertlane zimske obuće) nađoh odgovor u pitanju. Možda realnost nije dovoljna?

Pisati o bibliotekama, bibliotekarima i bibliotekarstvu na Balkanu znači pisati u stilu magijskog realizma. Da podsjetimo, magijski realizam je „oznaka za tip pripovjedne proze koju odlikuje neproblematično spajanje suprotstavljenih perspektiva, jedne zasnovane na racionalnim i jezičnim strukturama zapadnoeuropskoga književnog realizma i druge koja prihvaća nadnaravno kao prozaičnu stvarnost. "ㄹ Ovaj pristup omogućava da opišemo (dokumentiramo) stvarnost u kojem je ono Kako mali Đokica zamišlja bibliotekarstvo potpuno realno, moguće, izvodljivo i nadasve društveno prihvatljivo.

I zaista, sada je već lakše.

\footnotetext{
${ }^{1}$ Dugujem zahvalnost Monji Šuta-Hibert na dostavljenom istraživanju, istraživačkom materijalu te zabilješkama istraživača, bez koje ovaj rad ne bi postojao. Zahvaljujem Vedranu Kolovratu na saradnji u jezičko-stilskoj i dokumentacijskoj obradi rukopisa i na beskrajno duhovitim komentarima, bez kojih bi ovaj rad bio mnogo dosadniji. Zahvaljujem Mariju Hibertu na diskusijama o profesionalnom osposobljavanju bibliotekara i kadrovskoj politici.

2"Magični realizam", u Hrvatska enciklopedija [online izdanje], preuzeto 25. 10. 2019, www.enciklopedija.hr.
} 
Ako pogledamo teorijski okvir magijskog realizma, i najnevjernijem Tomi u redakciji, a i čitalištu, biće jasno zašto je ovaj model potpuni hit. Kako kaže gospođa Wendy Farris ${ }^{3}$ (a ona je ekspert), tekst iz žanra magijskog realizma karakterišu sljedeće osobine:

a) sadrži "nesvodljive elemente" magije (onaj koji ne može biti pojednostavljen, onaj koji se ne može transformirati u željeno stanje). Datost je ta koja je skoro aksiomatska i ne dokazuje se. Primjer je neshvaćenost bibliotekara u društvu, kao i njegovo stručno magijsko pripovjedanje o stručnosti stečenoj na stručnom ispitu. Najbolji primjer magijskog je sticanje zvanja bibliotekar. Naime, neki ljudi završe studij bibliotekarstva u trajanju od četiri godine i steknu zvanje bibliotekar, a neki završe kurs na stručnom ispitu u trajanju od četiri dana i steknu zvanje bibliotekar. Ovaj fenomen nije poznat niti u jednoj drugoj struci. Nadalje, valjda jedino u bibliotekarstvu su identificirani primjerci koji tvrde da više vole bibliotekarstvo od rođenog djeteta (mitologizirana ljubav nasuprot empirijskih dokaza o privrženosti prema biološkim srodnicima).

b) opisi u magijskom realizmu sadrže detaljnu prisutnost pojavnog svijeta (doduše iskrivljenu očima bibliotekara). Svjedok tome su bespregledni tomovi i tomovi zbornika radova o zavičajnim zbirkama (i drugi utezi za papir), koji rijetko donose kritičku analizu, nego beskrajno popisivanje beskrajne građe o beskrajno malom zavičaju, kao i beskrajne (bio) bibliografije beskrajno nebitnih života i djela uglavnom (ne)zaslužnih pojedinaca kojima nastojimo raskrčiti mjesto u istoriji ili na akademskim kandidatskim listama.

c) čitatelj može osjetiti određene sumnje u pokušaju usklađivanja dvaju suprotstavljenih shvaćanja događaja (na primjer korisnikovu i bibliotekarovu, a kao meta-shvatanje se može uvesti razumijevanje nadležnog ministarstva). Najbolji primjer je budžet za bibliotečku djelatnost i očekivanje dodate vrijednosti. Za beskrajno mali budžet očekuje se pomjeranje planina, a zna se da bibliotekari nisu baš vični alpinizmu. Nadalje, kontaktna tačka upravnik biblioteke - bibliotekar je također mjesto (ne)sporazuma. Upravnik je često politički podobni namještenik koji se u biblioteke razumije kao Mara u svoju čuvenu električnu gitaru, u narodu poznatu kao tambura.

d) naracija spaja različita područja, odnosno stvarni svijet i nadnaravne norme

Čuveni glagol koji spaja stvarni svijet i nadnaravno je TREBATI koji je u širokoj upotrebi u bibliotečkom diskursu svakodnevice: trebalo bi ovo sve digitalizirati, trebalo bi ispitati korisničke potrebe, trebalo bi obraditi svu građu u biblioteci, trebalo bi napraviti reviziju i otpis, trebalo bi nabaviti novu kopir-mašinu, trebalo bi nabaviti novi rešo za kafu, trebalo bi povećati plate, trebalo bi isplatiti regres, trebalo bi promijeniti zakon. Dalji primjer je upotreba mudrosti Riješiće se već nešto, gdje djelatni subjekt nije poznat ni bibliotekaru, ni korisniku, ni nadležnom ministarstvu. Također, na glasu je i od stručne javnosti pozdravljeno ritualno ponavljanje UNESCO-vih načela, bez imalo grižnje savjesti u njihovom nesprovođenju.

e) magijski realizam narušava ideje o vremenu, prostoru i identitetu ${ }^{4}$ (ovdje je svaki komentar izlišan, ali zaista).

Iz ovih pet naučno utemeljenih pretpostavki, koje generiraju vrlo jasne hipoteze, idemo u istraživačku ekspediciju.

Naime, radi se o sljedećem.

\footnotetext{
${ }^{3}$ Wendy Farris, Ordinary Enchantment, Magical Realism and the Remystification of Narrative (Nashville: Vanderbilt University Press, 2004).

${ }^{4}$ Farris, Ordinary Enchantment, Magical Realism and the Remystification of Narrative. Nabrajanje je naše. Dodaci u kurzivu u uglastim zagradama su naši. U izvorniku stoji: "First, the text contains an 'irreducible element' of magic; second, the descriptions in magical realism detail a strong presence of the phenomenal world; third, the reader may experience some unsettling doubts in the effort to reconcile two contradictory understandings of events; fourth, the narrative merges different realms; and, finally, magical realism disturbs received ideas about time, space, and identity".
} 


\section{Bibliotekar, kako to gordo zvuči}

Biti bibliotekar u 21. vijeku na Balkanu podrazumijeva prije svega vještine preživljavanja: društveno marginaliziran i odbačen od strane drugih profesionalnih zajednica, nastoji kreirati poticajno okruženje za provođenje vrijednosti sadržanih u Strategiji Međunarodne federacije bibliotečkih asocijacija i institucija 2019-2024, ${ }^{5}$ kroz:

- Usvajanje principa slobode pristupa informacijama, idejama i umjetničkim djelima te slobode izražavanja utkanim u član 19 Univerzalne deklaracije o ljudskim pravima.

- Vjerovanje da bi narodi, zajednice i organizacije trebalo da u potpunosti i na pravedan način ostvaruju pristup informacijama, idejama i umjetničkim djelima, a radi njihovog društvenog, obrazovnog, kulturnog, demokratskog i ekonomskog blagostanja.

- Uvjerenje da pružanje visoko kvalitetnih bibliotečkih i informacijskih usluga pomaže pri osiguravanju tog pristupa.

- Obaveza da se svim članovima Federacije omogući uključivanje u, i korištenje njenih aktivnosti bez obzira na državljanstvo, invaliditet, etničku pripadnost, spol, geografsku lokaciju, jezik, politička uvjerenja, rasu ili vjeru.

Ovi uzvišeni magijski principi podrazumijevaju vrlo visok nivo profesionalizma, znanja, kompetencija i vještina koji se očekuju od bibliotekara i bibliotekarki. Da li oni mogu provesti i afirmirati navedene vrijednosti svojim svakodnevnim radom? Da li su bibliotekari i bibliotekarke spremni stati na bedem odbrane ovih principa i profesionalno odgovoriti tim izazovima?

Da bismo odgovorili na ova i slična pitanja, vrijeme je da pođemo na uzbudljivo putovanje, u Sarajevondo, danas poznatiji kao Kanton Sarajevo. Sarajevondo je, kao i njegov grad pobratim Macondo, bio izložen raznim nedaćama i dijele gotovo istu sudbinu. I u Sarajevondu je skoro četiri godine neprestano lila kiša.

Početkom ljeta gospodnjega dvijehiljadeipetnaeste godine, tri istraživača su se zaputila u ovaj zaboravljeni grad da ispitaju koliko su i kako bibliotekari i biblioteke u skladu sa zakonima ovog magijskog područja, kao i sa presvijetlim i uzoritim načelima propisanim u međunarodnim magijsko-esnafskim standardima. ${ }^{6}$ Ovdje donosimo sažetak i komentar ovog istraživanja, kojeg su prekrile trska i šaš interesovanja naših naroda i narodnosti.

Ako neko slučajno misli da su podaci iz 2015. godine bajati i nedovoljno svježi, dozvolite da uputim na moj omiljeni citat koji je napisan prije ravno 49 godina (a koji zvuči kao da je pisan juče), dakle, davne 1970. godine, kada je rađena posljednja (nama poznata) potpuna analiza stanja bibliotekarstva u Bosni i Hercegovini:

"Ni nedavno usvojeni Zakon o visokom školstvu u Republici ne pominje značaj biblioteke u nastavnom procesu, kao ni njen položaj unutar visokoškolske ustanove. Reforma univerziteta koja predviđa sve veće učešće studenata u nastavnom procesu ne može zaobići ni bolje opsluživanje studenata i nastavnika... Nužno je da biblioteke visokoškolskih ustanova budu njihov integralni dio i da imaju jasno određen status u sklopu matičnih ustanova pri kojima djeluju". ${ }^{7}$

Sve je isto samo njega nema. Vjerujte mi, podaci iz 2015. kojima raspolažem sasvim su dovoljno svježi. I hrskavi.

5 IFLA, IFLA Strategy 2019-2024, preuzeto 25. 10. 2019, https://www.ifla.org/strategy.

${ }^{6}$ M. Šuta-Hibert, E. Muhović i V. Nurkić, Analiza stanja školskih biblioteka osnovnih i srednjih škola Kantona Sarajevo (Sarajevo: Školegijum, 2015), preuzeto 25. 10. 2019, http://www.skolegijum.ba/static/files/biblioteka/pdf/55911ab148332_Analizastanjaskolskihbiblioteka.pdf.

${ }_{7}$ Republički sekretarijat za obrazovanje i kulturu [et.al.], Analiza o stanju bibliotekarstva u Bosni i Hercegovini (Sarajevo, 1970), 69. 


\section{Istraživači međ' javom i međ' snom}

Vjerujući u sve proklamovane principe u debelim knjigama, istraživači su došli u Sarajevondo da pričaju sa bibliotekarima i bibliotekarkama. Obišli su ukupno 81 biblioteku. Hvale vrijedan uzorak. U tom uzorku su pronašli raznolika bića u vrlo sumorno sličnim i teško dostupnim bibliotečkim habitatima. Loše grijanje, buđ i iščekivanje regresa, pojačani izrazitim nivoima klaustrofobije po metru kvadratnom.

Analizirajući kadrovsku politiku u osnovnim i srednjim školama Kantona Sarajevo, istraživački tim navodi da je zapošljavanje (ne)stručnih osoba u školske biblioteke jedna od najkontroverznijih i možda najsloženijih problematika kada je u pitanju položaj školskih biblioteka u Kantonu Sarajevo. ${ }^{8}$ Od ukupnog broja od 89 intervjuiranih bibliotekara, samo 34 imaju završen studij bibliotekarstva. Ostali zaposleni imaju isključivo položeni stručni ispit, osim u jednom slučaju, u kojem uposlenik nema ni odgovarajuću školsku spremu ni stručni ispit. Ovakav podatak sam po sebi implicira alarmantno stanje, ukazujući na suštinsku neusklađenost kadrovskih praksi sa zakonskim i podzakonskim okvirom. Utvrđeni procenat od 68\% neadekvatno obrazovnih kadrova bi vjerovatno kod normalnog istraživača potakao poriv da istraživanje i izlaganje privede kraju. Svako dalje elaboriranje, pravdanje i posipanje pepelom je neumjesno i neprihvatljivo. Zapravo, empirijski je dokazano da samo trećina bibliotekara zaposlenih u školskim bibliotekama može odgovoriti izazovima koje pred njih stavlja Okvir vještina za profesionalce u bibliotekama i muzejima za 21 vijek. ${ }^{9}$ Naime, set predviđenih vještina uključuje kritičko mišljenje i rješavanje problema, kreativnost i inovativnost, komunikaciju i saradnju, bazičnu pismenost, vizuelnu pismenost, naučnu i numeričku pismenost, krosdisciplinarno mišljenje, informacijsku i medijsku pismenost, ICT pismenost, fleksibilnost i prilagodljivost, samoinicijativnost i samo-usmjeravanje, socijalne i kroskulturalne vještine, produktivnost i odgovornost, liderstvo, globalnu svjesnost, finansijsku, ekonomsku i poduzetničku pismenost, građansku, zdravstvenu i okolišnu pismenost.

Neko bi mogao reći da sa bilo kojom diplomom možete imati ove vještine. Poenta je u integraciji ovih vještina u već stečene profesionalne kompetencije, sa već jasno utvrđenim ishodima učenja u bibliotečkoj struci. Izvedbu omeđenu kontekstom bibliotečke prakse zatim je potrebno prilagoditi svakom pojedinačnom korisniku, uzimajući u obzir sijaset parametara. Čini se da bibliotekar 21. vijeka tipski odgovara antičkom heroju, na brisanom prostoru, između boga i čovjeka. Teško da heroj može postati neko tek tako, sa položenim kursom i jednim kišnim petkom u biblioteci.

Zašto već godinama bježimo od osnovne premise da u bibliotekama moraju raditi diplomirani bibliotekari? Kako od te premise ne bježimo u drugim strukama kada kažemo da na mjestu ljekara ne mogu raditi osobe koje su završile kurs prve pomoći? Zašto od te premise ne bježimo kada kažemo da pravosudni ispit mogu polagati samo diplomirani pravnici? Zašto uporno pristajemo da bibliotekar može biti bilo ko? Samo sa završenim kursom? Pa na kraju krajeva, zašto jezik u školama ne bi mogle predavati osobe koje su završile analfabetski tečaj? Znaju sva slova. Evo na primjer, pisac ovih redova ima završen kurs iz pravljenja divit baklave, a ipak, da bi otvorio poslastičarnicu, moram imati završen poslastičarski zanat. A znamo da svi kući prave kolače. Da li se kućna radinost može izjednačiti sa profesionalnim angažmanom?

Mislim da ne.

U bibliotekama jednostavno moraju raditi bibliotekari.

Međutim, zatečeno stanje u školskim bibliotekama ima i vrlo jaku socijalnu dimenziju. U istraživačkim dnevnicima našli smo zanimljive magijske marginalije, teško čitljive zabilješke istraživačkog tima, koje su bile natopljene ili kišom, ili suzama istraživača. Stvar je bila dodatno otežana jer je kiša padala za vrijeme cjelokupnog istraživačkog procesa. Jedna od zabilješki kaže

\footnotetext{
8 Šuta-Hibert et al., Nav. delo, 16.

9 Institute of Museum and Library Services, Museums, Libraries and 21st Century Skills, preuzeto 25. 10. 2019, https://www.imls.gov/ issues/national-initiatives/museums-libraries-and-21st-century-skills.
} 
da je, prema iskazu jednog od ispitanika, biblioteka mjesto gdje rade osobe koje su tu da odrade posljednje radne dane, ili osobe koje nemaju nastavne norme (možda predaju predmete koji više nisu u "modi", npr. ruski, turski). Spominju se i teško bolesni (u tri slučaja), jer u nastavi više ne mogu raditi, a kako kažu sudionici istraživanja "da dobiju otkaz, ne ide".

lako se na prvi pogled čini da ovo humano preseljenje isluženih nastavnika u školski podrum ima ljudsku notu, u osnovi čini najgrublji akt poniženja: ponuditi radniku radno mjesto koje nije u stanju obavljati i na kojem se i on loše osjeća, a njegovi klijenti još gore.

Samo u magijskom realizmu je moguće da se istovremeno implementira Program socijalne pravde i Program dugoročne društvene nepravde za koji će neko očekivati da može polučiti dobar rezultat.

Teško bolesni nastavnik koji više nije u stanju izvoditi nastavu najmanje zaslužuje da se na kraju karijere gurne u ćošak na još neadekvatnije radno mjesto. On zaslužuje mir. Mirovinu. A ne biti metom osude jer zauzima tuđe radno mjesto, odnosno žrtvom sitnih bibliotečkih mešetarenja.

U Sarajevondu je četiri godine lila kiša.

Neki ljudi osjećaju kišu. Ostali samo pokisnu. ${ }^{10}$

\title{
Literatura i izvori:
}

1. Farris, Wendy. Ordinary Enchantment, Magical Realism and the Remystification of Narrative. Nashville: Vanderbilt University Press, 2004.

2. IFLA. IFLA Strategy 2019 - 2024. Preuzeto 25. 10. 2019. https://www.ifla.org/strategy.

3. Institute of Museum and Library Services. Museums, Libraries and 21st Century Skills. Preuzeto 25. 10. 2019. https://www.imls.gov/issues/national-initiatives/museums-libraries-and-21st-century-skills.

4. „Magični realizam". U Hrvatska enciklopedija [online izdanje]. Preuzeto 25. 10. 2019. www.enciklopedija.hr.

5. Republički sekretarijat za obrazovanjeikulturu [et.al.]. Analiza o stanju bibliotekarstva u Bosni i Hercegovini. Sarajevo, 1970.

6. Šuta-Hibert, M., E. Muhović i V. Nurkić. Analiza stanja školskih biblioteka osnovnih i srednjih škola Kantona Sarajevo. Sarajevo: Školegijum, 2015. Preuzeto 25. 10. 2019. http://www.skolegijum.ba/static/files/biblioteka/pdf/55911ab148332_Analizastanjaskolskihbiblioteka.pdf.

\section{The Scent of Rain: The Personnel Policy of Transitional Librarianship in the Hilly Balkans}

\begin{abstract}
Summary
In this paper, the author presents an analysis of personnel policy in the libraries of the Canton of Sarajevo viewed through the perspective of the theory of magic realism as the only possible framework for explaining the employment phenomenon in the library profession. He gives a different reading of the data collected in a systematic survey of the state of libraries in primary and secondary schools in the Canton of Sarajevo, through the prism of the Strategy of the International Federation of Library Associations and Institutions for the period 2019-2024. Being a librarian in the Balkans in the $21^{\text {st }}$ century implies first and foremost the survival skills: socially marginalized and rejected by other professional communities, librarians seek to create a stimulating environment for the implementation of the values contained in the abovementioned document. Analyzing the personnel policy in primary and secondary schools in the Canton of Sarajevo, the research team states that recruiting (un)professional staff is one of the most controversial and perhaps most complex issues when it comes to the position of school libraries.
\end{abstract}

Keywords: libraries, personnel policy, school libraries, Bosnia and Herzegovina, magic realism 


\section{(2) $(\odot \otimes \Theta$}

Miris kiše: kadrovska politika tranzicionog bibliotekarstva na brdovitom Balkanu by Saša Madacki is licensed under a Creative Commons Attribution-NonCommercial-NoDerivatives 4.0 International License. 